\title{
Emotional Intelligence and Mental Health among Adolescents
}

\author{
Mary Rachelle R. Wapaño, PhD \\ Kinaadman Research Center, Xavier University - Ateneo de Cagayan, Philippines
}

\begin{abstract}
This study examined the role of emotional intelligence to mental health. In this study, the identified mental health components are anxiety, depression, self-efficacy, and resilience. This correlational research used regression analyses were conducted to examine the correlational relationships among variables The results showed the EI is negative predict anxiety and depression, and reactivity, a component of resilience. EI was shown to positively predict self-efficacy and resilience among 300Filipino adolescents. These results provide support for the idea that emotionally intelligent individuals are more likely resilient, have sense of self-efficacy and, are less anxious, less depressed, and less reactive. The results then demonstrate the adaptive value of emotional intelligence, that is, it allows an individual to positively cope and adjust to his/her environment.
\end{abstract}

\section{INTRODUCTION}

$\mathrm{E}$ motional intelligence is thought to be the individual's ability to process and utilize emotional information related to key areas of effective functioning in everyday life (Mayer \& Salovey, 1997). It is a combination of factors that is found to be related to motivation (Christie, Jordan, Troth, Lawrence, 2007); impulse control (Tice, Bratslavsky, \& Baumeister, 2001); mood regulation (Gohm) 2003 and the ability to persist in the face of frustration (Yoo \& Salovey, 2008). Evidence reveals that emotional intelligence is a predictor of academic (Downey, Mountstephen, Lloyd, Hansen, \& Stough, 2008) and professional (Abraham, 2005) success.

Among adolescents, emotional intelligence is found to help reduce stress by decreasing conflict, improving relationships and understanding one's own emotions. This kind of emotional health is fundamental to effective learning and education (Serrat, 2009). Understanding the process and elements of learning, which necessarily involves self-efficacy, self-regulation, and ability to communicate and cooperate, in themselves essential aspects of emotional intelligence, are also critical to student success (Zimmerman, Bandura, \& Pons, 1992). Stressful events, such as starting college life, moving to a new city, separation from friends, or loss of a parent, can prompt the onset of anxiety symptoms among adolescents. Among adolescents, anxiety disorder can be difficult to diagnose as an adolescent's behavior is often attributed to being "just a phase." When not addressed or left untreated, anxiety disorders can persist and interfere severely with an adolescent's life and can lead to missed school days, strained peer relations, low self-esteem, alcohol or substance abuse (Stein \& Hollander, 2001).
Moreover, anxiety is the most common emotional and mental health problems that occur during adolescence. As many as 1 in 10 adolescents suffer from anxiety disorder, with more females than males affected (Bell, Foster, \& Mash, 2005). This is consistent with the study of Lewinsohn, Lewinsohn, and Allen (1998) which showed prevalence of anxiety disorders among females, and that this prevalence appears early in life, at age six, and that females are shown to be twice as likely to experience anxiety disorder than are males. About half of adolescents with anxiety disorders are co morbid with other mental or behavioral disorders, or with a second anxiety disorder, depression (Aina \& Susman, 2006).

Among adolescents, depression can be a temporary response to stressors (Chua, 2002). A depressed mood is not uncommon due to maturation, the stresses connected with it, the impact of hormonal changes, and independence issues with parents. The study of Dulcan and Wiener (2006) showed that depression, as is anxiety, is difficult to diagnose in adolescence as normal adolescent behavior is marked by fluctuations of moods.

Depression is also manifested differently among adolescents. Prolonged emotional pain may also lead to serious physical problems as in erratic eating and sleeping habits (Foa \& Andrews, 2006). When left unrecognized, unaddressed or untreated, depression and anxiety impact every aspect of an adolescent's life (Saluja, Iachan, Scheidt, Overpeck, Sun, \& Giedd, 2004).

On the other hand, studies have shown that emotional intelligence has a protective effect against suicidal ideation and attempts (Cha \& Nock, 2009); against stress (Mikolajczak, Menil, \& Luminet, 2007); and against depression (McDougall, 2006). Moreover, studies reveal that emotional intelligence has a facilitative effect on overall health and life satisfaction (Landa, Zafra, Martos, \& AguilarLuzón, 2006).

This study also conceptualizes EI as significantly related to resilience and self-efficacy. Specifically, this research predicts that certain dimensions of the EI branch, employing emotional knowledge, labelled as flexible thinking, creative thinking, redirected attention and motivation (Mayer \& Salovey, 1990) are linked to resilience and self-efficacy. Furthermore, this study, self-efficacy is conceptualized as a person's beliefs about his capabilities to produce a certain level of performance that exercise influence over events that affect his life (Bandura, 1998). 
Resilience is defined in this study as the ability to effectively adapt the demands of one's environment, to maintain an optimistic attitude despite demanding situations, to deal with adversity or to recover from a negative experience (PrinceEmbury, 2007). Two resilience sub constructs are used in this study: mastery, defined as the ability to affect one's environment and involves optimism and adaptability; and emotional reactivity, defined as a predisposition for arousal or threshold of tolerance to stimulation (Prince-Embury, 2007). This study conceptualized depression as a consequence of affect-laden cognitions (Beck, 1961). The three main dysfunctional belief schemas dominate a depressed person's thinking are referred to as the cognitive triad: "I am defective or inadequate"; "All of my experiences result in defeats or failures"; and, "The future is hopeless." When these beliefs are present in someone's cognition, depression is likely to occur.

In this study, anxiety is conceived as anxiety proneness, that is, as a personality trait (A-trait) (Spielberger, 1983). Trait anxiety reflects the existence of stable individual differences in the tendency to respond with anxiety in the anticipation of threatening situations.

This study hypothesized that emotional intelligence is positively associated with resilience and self-efficacy, and negatively related to -emotional reactivity, depression and anxiety. The independent variable of this study is emotional intelligence, and the dependent variables are resiliencemastery, self-efficacy, emotional reactivity, depression, and self-efficacy.

This study seeks to investigate the relationship of EI to adolescent mental health:

1. What is the relationship of emotional intelligence to adolescent self-efficacy?

2. What is the relationship of emotional intelligence to adolescent resilience?

3. What is the relationship of emotional intelligence to adolescent anxiety?

4. What is the relationship of emotional intelligence to adolescent depression?

\section{LITERATURE REVIEW}

Adolescents face formidable challenges in emotional development (Conger \& Galambos, 1997). Their stilldeveloping sense of self and emotional competence correspond to the times when they face demands in school, or stresses in family life, and strong need to fit in among friends. The cost of emotional deficiency among adolescents is disturbing such as increased depression and anxiety (Fernández-Berrocal, Alcaide, Extremera, \& Pizarro, 2006) whereas developing their emotional abilities may improve their coping skills which in turn may produce better mental health in the long term (Downey, Johnston, Hansen, Birney, $\&$ Stough, 2010). The current EI studies are concerned with the model- and measure-development applied to managerial performance with adult respondents. Little research had been done that examined the adaptive function of emotional intelligence among adolescents (Malekar \& Mohanty, 2009).

\section{Emotional Intelligence}

The Mayer and Salovey EI model (Salovey \& Mayer, 1990) integrates key concepts from the theories of intelligence and emotion. The notion that intelligence involves the capacity to carry out abstract reasoning comes from intelligence theory while the notions that emotions are indicators that communicate general and understandable meaning about relationships and that certain emotions are basic as they are universal come from emotion research (Mayer, Salovey, \& Caruso, 2002 ). The Mayer and Salovey model proposed that there are individual differences in how people process emotion-laden information and how they relate emotional processing to general cognition. They further conceive of this emotional ability to manifest itself in certain adaptive behaviors.

Based on the model of intelligence, the Mayer and Salovey EI model attempts to define emotional intelligence within the context of the standard criteria for intelligence (Mayer, Salovey, Caruso, \& Sitarenios, 2003). This model proposes that emotional intelligence is composed of two areas: (a) experiential ability, which is the ability to perceive, respond and, regulate emotion without the necessity of understanding; and (b) strategic ability, which relates to the ability to understand and manage emotions without the necessity of adequate perception of feelings. In turn, each area is segregated into two branches, hence, the term "four branch model." The four branch model of EI then refers to the four areas of competencies that collectively illustrate the divisions of emotional intelligence. This model describes EI as divided into four areas: (a) emotional perception, (b) emotional assimilation, (c) emotional understanding, and (d) emotional management (Mayer, Salovey \& Caruso, 2004).

Branch 1, emotional perception, the initial and basic area, and involves the capacity to identify emotion in others' facial and postural expressions. This includes the nonverbal perception and reception of emotions expressed via the face, voice, and other related communication (Ekman \& Friesen, 1975, as cited in Mayer et al., 2004). Branch 2, emotional assimilation, involves the capacity of emotions to guide the cognitive system and promote thinking This branch, also referred to as "emotional integration" focuses on the contribution of emotion to logic and reasoning (Mayer, Salovey \& Caruso, 2000). Branch 3, emotional understanding, represents the ability to analyze emotions, understand their probable patterns over time, and recognize their outcomes. The development of this branch corresponds with the development of language and propositional thought (Mayer, Salovey, \& Caruso, 2004).

The Branch 4, emotional regulation, represents emotional management to promote emotional and intellectual growth. Openness to emotions is the initial point of emotional regulation (Mayer, 2001). 


\section{Emotional Intelligence and Adolescent Mental Health}

Mental health may be defined from a deficit model and a positive model. In the context of deficit model, mental health may be described as the absence of or lack of diagnosable disease. On the other hand, from the positive model, mental health is defined as a state of physical, social, and mental well-being (Creek \& Lougher, 2008). The definition from the World Health Organization (2005) corresponds closely to the positive conception of mental health: that it is as a state of "well-being in which the individual realizes his or her abilities, can cope with normal stresses of life, can work productively and fruitfully" (p.18).

The Health Education Authority (1997, as cited in Creek, Lougher, \& Van Bruggen, 2008) described mental health as the form of emotional and spiritual resilience, the ability to withstand taxing demands and daily challenges. The Scottish Public Mental Health Alliance (2002, as cited in Creek and Lougher, 2008) proposed that mental health as a positive resource that enables one to cope with life's demanding conditions and identified sense of self-worth and esteem, empathy, the ability to express emotions, to form and maintain healthy relationships, to effectively communicate as core attributes of an individual with positive mental health.

Mental health is also conceived as a continuum in which individuals vary on a progression of values (Keyes, 2009). This notion of mental health as a continuum conceives of mental health as positive and adaptive functioning on one end, and negative and impaired functioning on the other end (Tsai, 2005). The positive and adaptive end of mental health continuum involves the ability to adapt to change and cope with adversity and to effectively produce positive change. The other end of the continuum involves conditions characterized by changes or abnormalities of mood, thinking or behavior (Alexander, Larosa, \& Alexander, 2009).

Studies have shown evidence for the relationship between emotional intelligence and mental health. The study of Gupta and Shusil (2010) revealed the positive correlation between emotional intelligence and mental health among college students. Other related studies such as that of Velasco, Fernandez, Paez, and Campos (2006) found evidence of the relationship of emotional intelligence to life adjustment of university students. Fernandez-Berrocal, Alcaide, Extremera, and Pizarro (2006) found evidence that the ability to regulate mood among adolescents was positively related to selfesteem; that self-reported emotional intelligence was negatively related to depression and anxiety; and that the ability to discriminate among feelings and the ability to regulate emotional states are linked to better mental health.

Some studies have provided support for the correlational nature of emotional intelligence in adolescent adjustment: For example, Rubin (1999) showed that among adolescents, emotional intelligence was inversely related to aggression; Trinidad and Johnson (2002) revealed that higher emotional intelligence scores were related to lower smoking and alcohol use among high school students. Likewise, Mayer et al. (2001) suggested that emotional intelligence appears to be related to adolescents' ability to organize emotions that affect their peer relationships.

Evidence also showed that adolescents with high perception of their emotional abilities, specified as high emotional clarity and repair, generally reported better life adjustment, defined in terms of lower perceived stress and higher life satisfaction (Extremera, Duran, \& Ray, 2006). Moreover, Wong and Ang (2007) explored the relationship between emotional competencies (i.e., intrapersonal skills, interpersonal skills, adaptability skills, and stress management) with four factors of maladjustment (i.e., antisocial behavior, anger control problems, emotional distress, and negative self-problems) in an Asian sample. Their results indicate that stress management skills significantly predict overall maladjustment, antisocial behavior, anger control problems, emotional distress and negative self-problems among adolescents. Interpersonal skills significantly predicted negative self-problems whereas intrapersonal skills and adaptability did not significantly predict maladjustment factors. There is, then, growing support that emotional intelligence among adolescents is related to positive behavioral and social outcomes. The studies mentioned above show that emotional abilities are an important and unique contributor to mental health, but there is still a need for more research aimed at validation of these claims among adolescent samples. To date, there exists a knowledge gap on causal associations of some of EI predictors, EI, and mental health.

\section{Emotional intelligence and resilience}

Prince-Embury (2007) defined resilience as the "ability to weather adversity or to bounce back from a negative experience" (p. 11). She also identified the three constructs of resilience that allow for a multidimensional understanding and assessment of resilience, namely, sense of mastery, sense of relatedness, and emotional reactivity. This study focused on sense of mastery and emotional reactivity as literature suggests that these two are closely related to emotional intelligence.

Emotional reactivity is viewed as a person's susceptibility or threshold of tolerance to stimulation prior to adverse experiences. The aspects of emotional reactivity include sensitivity, recovery, and impairment (Prince-Embury 2008). Sensitivity is viewed as the threshold of and intensity of emotional response; recovery relates to the ability to return normal functioning after an intense emotional experience; and impairment is the extent to which one is able to maintain emotional balance when emotionally aroused. Research findings suggest a significant relationship between emotional reactivity, emotional regulation and resilience. For example, Eisenberg, Spinrad, Fabes, Reiser,

Cumberland, and Shepard (2004) revealed a significant interaction between the early experience of the child, the development of emotional reactivity, ability for self- 
regulation, and beginnings of psychological dysfunctions. Thus, emotional reactivity within the average range and that is manageable is an important aspect of resilience (PrinceEmbury, 2007).

Mastery affords an individual to directly affect his or her environment, and involves optimism, adaptability, and selfefficacy. Research has also found relationships between EI and optimism (Extremera, Duran, \& Rey, 2007), and EI and adaptability (Landa, Martos, \& Zafra, 2010). Some studies also point to the relationship between emotional intelligence and resilience. Connor and Slear (2009) examined the association between emotional intelligence, anxiety, and resilience. The results indicated that there exists a positive and significant relationship between emotional intelligence and resilience. From the results, the authors suggested that education must address these particular variables.

However, there is clearly a gap in the literature that examines the relationship between emotional intelligence and resilience among adolescent samples, as most studies targeted adult samples. To date, no existing studies have been found that examined the connection of EI predictors, EI and resilience.

\section{Emotional intelligence and self-efficacy}

Mayer and Salovey (1990) argued that emotions "subtly but systematically influence some of the component and strategies in problem solving" (p. 196) in four ways: First, emotional transitions may facilitate the production of several alternative plans. Second, positive emotions may change the organization of memory so that cognitive information is better incorporated and differing material are considered as more related. Third, Mayer and Salovey (1990) also suggest that emotion provides "interrupts for complex systems," (p. 196) removing them from a routine level of processing and focusing them on more crucial needs. And last, emotions and moods may be used to encourage and enhance performance at complicated intellectual activities (Mayer \& Salovey, 1990).

Mayer and Salovey proposed (1990) that moods assist in flexible planning, creative thinking, and in the redirection of attention. Moods may facilitate flexibility in planning in that changes in mood assist people in unpleasant moods to break their negative emotional set. As a result, they will then be more likely to generate alternate future plans for themselves. Moods may also assist creative thinking and problem solving through its impact on the organization and information-use in memory. For example, it is easy for people to classify problem features as related or unrelated while they are in a pleasant mood (Isen \& Daubman, 1984, as cited in Mayer \& Salovey, 1990). Creative problem solving may be influenced by the positive impact of clarity in classifying information.

Powerful moods re-direct attention to new problems. When an individual attends to his emotions, it is possible that he is directed away from the present problem, and is led to a new concern of critical importance. In this manner, individuals learn to make the most of the ability of emotional processes to re-direct attention to the most relevant stimulus in their environment. Mayer and Salovey (1990) proposed that "affect can help individuals to reprioritize the internal and external demands on their attention, and allocate attentional resources accordingly" (p. 198). In sum, Mayer and Salovey (1990) maintained that when individuals approach life tasks with emotional intelligence, they will be able to solve their "problems adaptively" (p. 199) They assert that the kinds of problems people recognize and the way they understand them is, most likely, framed within an internal emotional experience. Placing a problem in an emotional frame, individuals are allowed to be creative and flexible in generating potential alternative solutions to problems and will tend to integrate emotional aspects when choosing from among problem-solutions. This approach leads to behaviours that are "considerate and respectful of the internal experience of themselves and others" (p. 200).

\section{Relationship of EI to Depression and Anxiety}

Mayer and Salovey (2001) hypothesized that individuals have different expectancies on the ability to alleviate negative moods: there are those who believe in their capacity to manage their emotions and in their ability to respond actively to stress. There are others who are not confident in their ability for self-mood-regulation. Catanzaro and Greenwood (as cited in Mayer \& Salovey, 2001) found that individuals with low self-efficacy for regulation manifest avoidance responses, depressive, and mild somatic symptoms. Although the model shows that individuals need to attend to their moods to recognize those that require regulation, the Mayer and Salovey model further suggests that mere "attention to moods may not always be adaptive" (p. 287). Goldman, NolenHoeksema, Morrow, and Frederickson (as cited in Mayer \& Salovey, 2001) found that attention to one's moods relates positively to depression and neuroticism. For example, Swinkles and Guiliano (as cited in Mayer \& Salovey, 2001) found that high mood-monitoring individuals are prone to experience stronger emotional states and greater negative affect. Mood-monitoring, although a neutral activity, may increase rumination and consequently, extend negative affect experience (Nolen-Hoeksema, 1991, as cited in Mayer \& Salovey, 2001).

Mayer and Salovey (2001) suggest that the clarity in discriminating among moods is related to lower social anxiety, depression and physical symptom -reporting as well as to optimism and satisfaction with social and familial relationships. Salovey (2000) found that individuals who discriminate clearly their affective states ruminate less after a negative incident than individuals who report being unclear about their emotions.

Although mood-monitoring is found to promote rumination, mood-labeling enables people to develop adaptive strategies for dealing with their moods. The model suggests that individuals need to first attend to their moods in order to distinguish among them. When one is able to recognize and 
classify his moods, it enables one to prolong or change them. Mayer and Salovey (2000) posit that when attention to moods is not accompanied with discrimination of moods, the process becomes maladaptive that can lead to rumination, which in turn, leads individuals to extremely focus on their mood states without understanding why they are experiencing them. Rumination tends to intensify depression, and consequently, leads to difficulty in dealing with taxing events.

\section{Emotional intelligence and depression}

In relation to depression, several studies have demonstrated a relationship between emotional intelligence and depression among university students. For example, the study of Extremera and Fernandez-Berrocal (2006) revealed that high levels of certain EI dimensions such as emotional clarity and mood repair were related to low levels of anxiety and depression, high physical, and social functioning, mental health, vitality, and general health. Furthermore, their study confirmed the correlational value of specific EI dimensions named as attention to emotion, clarity of emotion and mood repair to levels of depression and other areas related to mental, social, and physical health among university students.

A similar research by Downey, Johnston, Hansen, Schemberi, Stough, Tuckwell, and Schweitzer (2008) demonstrated a similar relationship between low emotional intelligence and depression: Their study showed that depressed individuals scored poorly in all emotional intelligence dimensions, which included expressing emotions and being self-aware, understanding the emotions of others, utilizing emotions to guide decision making, managing emotions, and controlling emotions, compared to their non-depressed counterparts.

Specific relationships between severity of depression and the EI dimensions of managing and controlling emotions appeared in the study of Ciarrochi, Deanne, and Anderson (2000). They found that emotional intelligence made a unique contribution to understanding the relationship between stress and three important mental health variables, namely, depression, hopelessness, and suicidal ideation. Their study showed that there is greater suicidal ideation among those low in managing their own and others' emotions. Moreover, Pons' (1997) path analysis result showed emotional intelligence to be positively related to an adaptive form of goal orientation and with life satisfaction and to be negatively related to depression symptomatology. There is, then, evidence from literature that shows a negative relationship between emotional intelligence and depression.

\section{Emotional intelligence and anxiety}

A negative relationship between emotional intelligence and anxiety is implied in much of the emotional intelligence literature. For instance the regression analyses results of Siu's (2009) study reported similar results: the poor use of emotions led to higher levels of problem behaviors, such as depression, aggression and delinquency while a higher degree of selfmanagement led to less anxiety. This study supported the study of Drago (2004) which indicated the relationship of student anxiety to certain emotional intelligence abilities. Using an Asian sample of college students from several universities in Guangzhou, China, Wang (2002) revealed that emotional intelligence scores were negatively correlated with anxiety level and depression. He concluded that emotional intelligence plays an important role in college students' mental health.

\section{RESEARCH METHODOLOGY}

\section{Research Design}

This study is a correlational research. As a correlational research, this work examined whether emotional intelligence is related to mental health. In this study, emotional intelligence is the predictor variable, where as, self-efficacy, resilience, anxiety, and depression are considered criterion variables in this study.

Research Setting This study was conducted in the Philippines.

Sampling Procedure in this study, to test individual predictors, the sample size was set at 300 . This study specifically targeted college students as it has been shown that there was increased frequency of mental health concerns among college students that need to be systematically addressed. Hence, purposive sampling was used in this study. Informed consent were sought from the participants.

Of the 300 respondents, 166 (55\%) were females and 134 $(45 \%)$ were males. The average age of respondents was 19.10 years $(S D=1.956)$.

\section{Data gathering technique}

In this study, eight assessment instruments were used. Reliability of all the measures was assessed.

\section{Trait Meta-Mood Scale (TMMS)}

The TMMS assessed the extent to which individuals attend to their feelings, the clarity of their experience of these feelings, and their ability to regulate their feelings. The TMMS is found to be useful in identifying core individual differences that describe emotionally intelligent individuals. Early EI studies by Mayer and Gaschke (1988) showed that individuals regularly reflect, monitor, evaluate, and manage their feelings; they termed this process as meta-mood experience. The TMMS is designed to assess "relatively stable individual differences in people's tendency to attend to their moods and emotions, discriminate clearly among them, and regulate them (Salovey, Mayer, Goldman, Turvey, \& Palfai, 1995, p.128). It is designed to measure three EI constructs, namely, attention to emotion, clarity of emotion, and emotion repair. Attention to emotion conveys the extent to which individuals notice and think about their feelings; clarity of emotions refers to the ability to understand one's moods; and emotion repair pertains to the degree to which individuals regulate their moods.

The TMMS is found to be an adequate operationalization of the aspects of emotional intelligence (Salovey et. al, 1995). 
This measure is able to assess individual differences in people's ability to understand, express, and regulate their feelings as well as their ability of using their feelings adaptively. The scales in the TMMS, namely, attention to feelings, clarity of feelings, and ability to regulate one's emotions are fundamental to emotional intelligence (Salovey, et al., 1995). Previously reported internal consistencies for each subscale are high attention to emotion, $\alpha=.86$; emotional clarity, $\alpha=.87$; and emotion repair $\alpha=.82$ (Salovey, et al., 1995). Validation studies have demonstrated that these constructs can be sufficiently differentiated from related constructs such as neuroticism and repression. The use of self-report measures to assess emotional intelligence "provides a straightforward and economical means for measuring individual differences in emotional functioning." (Zeider et al., 2009,

p. 27).A pilot study was conducted $(\mathrm{n}=30)$ to test the reliability of measures in August 2009. The TMMS was to found to have acceptable reliability (30 items; $\alpha=.78$ ).

The alpha coefficient obtained in this study was .66. The reliability coefficients of the TMMS subscales were as follows: attention to feelings (13 items; $\alpha=.62$ ); clarity of emotions (11 items; $\alpha=.45$ ), and repair of emotions ( 6 items, $\alpha=.51)$.

\section{General Perceived Self-Efficacy Scale (GSE)}

The General Perceived Self-Efficacy Scale (Appendix E) was used in this study to assess perceived self-efficacy. The construct of perceived self-efficacy reflects an optimistic selfbelief (Schwarzer, 1992). Responses to a 4-point scale to all 10 items are summed up to yield a final composite score which ranges from 10 to 40 . To score, responses made on a 4point scale are summed up for all 10 items to yield the final composite score with a range from 10 to 40 .

The Beck Depression Inventory Second Edition (BDI-II) (Appendix G) is a designed to assess the presence of severity of symptoms of depression listed in the Diagnostic and Statistical Manual of Mental Disorders Fourth Edition (DSMIV, 1994). This 21-item revised edition includes items that assess severe depression. Some items were revised to indicate increase or decrease in sleep or appetite, items previously named as body image, work difficulty, weight loss, somatic preoccupation were reworded as agitation, concentration difficulty, and loss of energy. Reported coefficient alpha for BDI-II is .92 for outpatients and .93 for college students. Construct validity of BDI-II has established (Steer, Ball, Ranieri, \& Beck, 1997). Factorial validity has also been confirmed for BDI-II for student sample as it measures cognitive-affective and somatic symptoms of depression (Whisman, Perez, \& Ramel, 2000).

Result from current reliability testing found the BDI-II, with sample of 300 , to be highly reliable (20 items; $\alpha=.86$ ).

\section{Trait Anxiety Inventory (TAI)}

In this study, anxiety is understood in the context of Spielberger's Trait-State theory. Spielberger (1983, cited by Groth-Marnat, 2009) distinguished between two anxiety constructs: transitory or state anxiety (A-state) and anxiety proneness as a personality trait (A-trait). State anxiety is defined as an unpleasant emotional arousal in face of threatening demands or dangers. A cognitive appraisal of threat is a prerequisite for the experience of this emotion (Lazarus, 1991).

Trait anxiety, on the other hand, reflects the existence of stable individual differences in the tendency to respond with state anxiety in the anticipation of threatening situations. In the study, only trait anxiety was assessed by the Trait Anxiety Inventory (TAI), as shown Appendix $\mathrm{H}$, which reflects a general tendency to respond with anxiety to perceived threats. Scores can range from zero to 60, with higher scores suggesting higher anxiety (Spielberger, Gorusch, \& Lushene, 1970). Using local norms, scores below 12 suggest low level of anxiety; scores between 19 to 39 suggest moderate anxiety; and scores 40 and above indicate high levels of anxiety.

Recent reliability testing found the TAI to be reliable (20 items; $\alpha=.76$ ).

\section{RESULTS AND DISCUSSION}

This section presents the findings of the study: description of the variables of interest, namely emotional intelligence, and mental health variables (i.e., perceived self-efficacy, resilience, anxiety and depression). The correlational relationships of the independent variables, emotional intelligence, and mental health variables are presented here as well

Emotional intelligence. As shown in Table 1, the respondents obtained mean score of 87.52 ( $\mathrm{SD}=9.08$ ) considered in the average range and suggesting an adequate awareness of emotions, clarity, and self-regulation. For EI subscale emotional attention, respondents reported average score 44.15 $(S D=5.98)$, suggesting a growing emotional awareness. For clarity of feelings, respondents obtained mean score of 24.90 ( $\mathrm{SD}=3.97$ ) considered as average scores, suggesting growing emotional clarity. For emotional repair, respondents obtained mean score of $15.50(\mathrm{SD}=2.64)$ in emotional repair, suggesting adequate ability at mood management.

\section{Description of Scores of Mental Health Variables}

Table 2 shows the mean and standard deviation scores of mental health variables, namely, perceived self-efficacy, resilience (with two subscales mastery and emotional reactivity), anxiety, and depression.

\section{Perceived self-efficacy}

On perceived self-efficacy, respondents obtained mean score of $29.41(S D=4.84)$, reflecting adequate self-efficacy, with sufficient beliefs on one's capacity to deal with stressors. 


\section{Resilience}

Resilience was measured using two measures, assessing two separate subscales: mastery and emotional reactivity. The respondents reported moderate in mastery $55.67(S D=8.30)$ reflecting adequate adaptability and optimistic attitude. On emotional reactivity, respondents reported slightly elevated score, $32.10(S D=13.11)$, reflecting emotional sensitivity and lower emotional threshold.

\section{Depression}

Respondents obtained a mean score of $18.67(S D=10.11)$ suggesting mild levels of depression characterized by somewhat downcast feelings, less sharpness in thinking, while continuing doing the essentials but with less conscientiousness, and with feelings of exhaustion.

\section{Anxiety}

Respondents obtained a mean score of $25.98(S D=7.01)$ for anxiety. This suggests a moderate level of anxiety, which involves state of discomfort, apprehension, fear, feelings of being threatened of vague risks.

\section{Emotional Intelligence Components as Predictors of Mental Health}

Multiple regression analyses were used to test components, namely emotional attention, emotional clarity, and emotional repair predict mental health. The results supported the hypotheses that EI and EI components significantly predicts self-efficacy, resilience, anxiety, and depression.

The regression results revealed EI scales to predict perceived self-efficacy $\left.\mathrm{R}^{2}=.058, F(3,296)=6.023, p<.01\right)$, with EI component emotional clarity significantly predicted selfefficacy $(\beta=.196, p<.01)$. Regarding effect size, $5.8 \%$ of the variability of perceived self-efficacy was explained by EI components. Statistical power, computed post-hoc was .68.

The results also showed EI scales to predict resilience-mastery $\left(R^{2}=.114\right.$,

$F(3,296)=12.662, p<.001)$, with emotional clarity predicting resilience-mastery $(\beta=.234, \mathrm{p}<$. 001) and emotional repair $(\beta=.176, p<.01) \quad$ Regarding effect size, $11.4 . \%$ of the variability of resilience-mastery was explained by EI components Statistical power, computed post-hoc was adequate at .98. Regression results are shown in Appendix A, regression results of EI scales and mental health variables.

Table 1 Means and Standard Deviation Scores of Emotional Intelligence, Perceived Parenting Styles and Temperament

\begin{tabular}{|c|c|c|c|c|}
\hline Variable & Subscales & $M$ & $S D$ & Range \\
\hline $\begin{array}{c}\text { Emotional } \\
\text { Intelligence }\end{array}$ & & 87.52 & 9.08 & $25-125$ \\
\hline & $\begin{array}{c}\text { Attention to } \\
\text { Emotions }\end{array}$ & 44.15 & 5.98 & $13-65$ \\
\hline & Clarity of Emotions & 24.90 & 3.97 & $8-40$ \\
\hline & Repair of Emotions & 15.50 & 2.64 & $12-20$ \\
\hline
\end{tabular}

Table 2 Mean and Standard Deviation Scores of Mental Health Components

\begin{tabular}{|c|c|c|c|c|}
\hline Variable & Subscales & $M$ & $S D$ & Range \\
\hline \multicolumn{2}{|c|}{ Perceived self-efficacy } & 29.41 & 4.84 & $10-40$ \\
\hline Resilience & Mastery & 55.67 & 8.3 & $0-80$ \\
\hline Resilience & $\begin{array}{c}\text { Emotional } \\
\text { reactivity }\end{array}$ & 32.10 & 13.11 & $0-80$ \\
\hline Depression & & 18.67 & 10.11 & $0-63$ \\
\hline Anxiety & & 25.98 & 7.01 & $0-60$ \\
\hline
\end{tabular}

EI scales also predict emotional reactivity, $\left(R^{2}=.120, F(3\right.$, $296)=13.459, p<.001)$, with clarity of emotions $(\beta=-.300$, $p<.001)$ and emotional repair $(\beta=-.161, p<.001)$ as significant predictors. Regarding effect size, $12 \%$ of the variability of perceived self-efficacy was explained by EI components. Statistical power, computed post-hoc was adequate at .98 .

EI scales significantly predict depression as well $\left(R^{2}=.076\right.$, $F(3,296)=8.106, p<.001)$, with clarity of emotions a significant predictor $(\beta=-.242, p<.001)$. Regarding effect size, $7.6 \%$ of the variability of depression was explained by EI components. Statistical power, computed post hoc, was .86 .

EI scales also significantly predict anxiety $\left(R^{2}=.170, F(3\right.$, 296) $=20.173, p<.001)$. Emotional clarity $(\beta=-.337, p<$ $.001)$ and emotional repair $(\beta=-.195, p<.001)$ were found to be significant predictors of anxiety. Regarding effect size, $17 \%$ of the variability of anxiety was explained by EI components Statistical power, computed post-hoc was adequate at .99 .

In sum, total emotional intelligence positively predicts perceived self-efficacy and mastery, and negatively predicts emotional reactivity, depression, and anxiety. EI components, which were found to predict mental health, were emotional clarity and repair.

The results support the hypotheses previously put forth, that emotional intelligence predicts adolescent mental health. Specifically, EI was found to positively predict perceived selfefficacy and the sub dimension of resilience, mastery; and negatively predicted anxiety, depression, and another sub dimension of resilience, emotional reactivity.

In terms of general mental health, evidence from research is consistent with these results. For example, Martinez-Pons (1997) revealed that individuals with higher EI levels experience better mental health; Gohm and Clore (2002) showed self-reported EI is related to self-reported well-being; O'Connor and Little (2003) also found that high EI individuals report fewer clinical symptoms, such as anxiety and depression; and Bar-On (2000) showed EI to relate to various measures of mental health. The sections below discuss the relationship between emotional intelligence and mental health components. 


\section{Emotional Intelligence and Perceived Self-efficacy}

In this study, self-efficacy is viewed as person's belief in his or her abilities to affect positively his or her performance or life events. The results have shown that emotional intelligence positively predicts perceived self-efficacy. The same results also showed that emotional clarity, the ability to understand and discriminate among feelings, is the EI component that significantly predicts perceived self-efficacy.

These results are consistent with the literature reviewed, which showed emotional intelligence as predictor of general perceived self-efficacy (Penrose, Perry, \& Ball, 2007; Villanueva, Sanchez, \& Howard, 2007). That emotional intelligence predicts perceived self-efficacy is explained by the Mayer and Salovey four-branch EI model (1990). This EI model proposed that individuals, who are able to understand their emotions, are likely to use this emotional knowledge to their advantage.

In the course of development, individuals develop the ability to reflect on their own emotions, or a meta-experience of their own moods. Expressions such as "this feeling is affecting my thinking," reflect an understanding of one's feelings that is distinct from a mere perception of mood. Mayer and Salovey (1997) theorized that emotional meta-experience may be classified as meta-evaluation and meta-regulation. Metaevaluation relates to the extent of attention one gives to one's moods, also the degree of clarity, and the extent of its influence. Meta-regulation pertains to the individual's attempts to improve an unpleasant mood or maintain pleasant ones.

Emotional insight, from meta-experience of mood, may then be applied to logic and reason. Emotions, they theorized, affect one's problem-solving strategies. For example, fluctuating moods may lead to alternate problem-solving plans, and that moods may be used a motivational cues to aid performance at demanding and complex tasks. The Mayer and Salovey EI model (1990) supposed that emotions may be utilized to positively address problems: Moods may be used to strengthen persistence in the face of taxing demands. Negative moods (e.g., anxiety), which may spring from evaluative situations, may be used as a motivator for thorough preparation, whereas positive emotions can be used to increase one's confidence in one's abilities. Salovey, Woolery, and Mayer (2001) have shown that persons with high EI have been found to have stronger sense of selfefficacy in terms of emotional regulation. They appear to be confident in their ability to repair distressful emotions with the strategies they have in their proverbial sleeves, as well as preserve appropriate positive moods. Salovey et al. (2001) predict that individuals who are able to see their feelings clearly and believe in their ability to manage their moods, are also likely to cope with the impact of stressful events.

It can then be thought that a keen awareness and understanding of one's feelings, the ability to regulate one's moods, and the willingness to utilize moods to move toward a goal or to face taxing demands, allow one to generate positive beliefs and confidence about one's capacity to deal with stressful demands.

Although this current work explored the predictor role of EI to perceived self-efficacy, future research work may examine the moderator role of EI to self-efficacy and other variables, such as academic achievement. This is to understand better EI's adaptive functions in other areas of adolescent life.

\section{Emotional intelligence and Resilience}

In this study, resilience was assessed as sense of mastery and emotional reactivity. The sense of mastery in resilience is viewed as a sense of competence and involves adaptability, optimism, and self-efficacy. The results also show that EI is a predictor of resilience-mastery. Additionally, the results also show that emotional clarity makes an important contribution to resilience-mastery. Mayer and Salovey's (1990) EI model explains that the ability to utilize emotions allows for flexible planning, creative thinking, and redirecting of moods. This EI model assumes that mood fluctuations carry with them corresponding expectations of future events. That is, people in positive moods expect positive events are likely to happen, and negative events as unlikely; whereas, people in unpleasant moods expect the reverse. Mood swings and the understanding thereof, may be utilized to allow individuals to consider alternate expectations and options. The change of mood from negative to positive allows one to generate alternate plans, thus, enable flexible planning.

Mayer and Salovey (1990) explained how moods assist problem solving by its effect on the organization and information stored in memory. They contend that positive moods, or optimism, allows for more clarity of problemrelated information which in turn allows for creative problemsolving. They suggest that the happier individuals are likely to categorize information and uncover relationships than their unhappier counterparts. It may be that a positive outlook facilitates the discovery of relationships, categories, and principles, which can be used to integrate information to generate the solutions to problems.

Moods, Mayer, and Salovey (1990) also theorized that moods redirect attention. Individuals can utilize emotions to redirect their attention from one issue to more pressing ones. Moods allow individuals to re-assess and re-prioritize demands. They can, then, choose which demands need the utmost attention. It can then be said, that emotional clarity allows people to assess alternative actions, keep their focus, thus allow them more adaptive coping strategies. Gohm and Clore (2002), and Extremera, Fernandez-Berrocal (2005) support this study's results. The cognitive model proposed by Stein, Trabasso, and Liwag (1993), offers another explanation for the relationship of emotional understanding and problem-solving. This model suggests that as emotional events happen, people appraise and, subsequently plan for courses of action that relate to the emotions being experienced. The model conceived of emotions as purposeful, that lead to directed 
actions and which sustain emotional well-being. Emotions, then, can be utilized as basis for sound judgment and for problem-solving.

Resilience is also assessed here in terms of emotional reactivity, and is alternatively known as vulnerability, arousability, or threshold of tolerance. Emotional reactivity includes, for its subscales, sensitivity which pertains to sensitivity and threshold of reaction; recovery, the ability to bounce back from emotional distress; and impairment, the extent to which one can maintain an emotional balance when under duress. With these subscales, high scores suggest increased vulnerability, low threshold of tolerance, inability to regain emotional balance after an emotional event.

The results of this study have shown EI to negatively predict emotional reactivity. Specifically, EI components emotional clarity and repair were found to negatively predict emotional reactivity. These results are in agreement with the study of Salovey, Mayer, Goldman, Turvey, and Palfai (1995) which reported that certain aspects of EI are related to emotional impairment and recovery, both of which are sub dimensions of emotional reactivity. Their results have also shown EI aspect (i.e., emotional clarity) to be a predictor of emotional recovery, which is also consistent with the results of this study.

Additionally, recent findings support this study's results on emotional repair to negatively predict emotional reactivity. Ciarrochi (2001) found differential emotional reactions of individuals with either high or low emotional self-regulation. In their experimental study, individuals high in emotional repair tended to report positive stories in positive mood conditions versus neutral conditions; whereas, individuals with low emotional repair were found to report more negative stories in negative mood conditions than in neutral ones.

One possible explanation for these results is offered by the Mayer and Salovey EI model (1990). Emotional clarity involves the appraisal and processing of emotional information. This process of emotional processing, allows one to recognize emotions, emotional meanings, and the relationships among them. That is, individuals with greater emotional clarity are more likely to have a better understanding of the emotional stimulus and emotional situation.

In turn, the theory presumed that individuals with adequate emotional insight are able to respond appropriately to their emotions. Individuals with emotional understanding are less likely to overreact to emotional situation, may be better able to recover from emotional events, and maintain some degree of emotional balance even under stress. Emotional clarity and emotional repair, then, appear to play complementary roles in emotional processing in its role to emotional reactivity: Emotional clarity appears to enhance emotional insight and improve mood, whereas emotional repair appears to regulate moods and repair negative emotional experiences.

\section{Emotional intelligence, Anxiety, and Depression}

The results support the hypothesis of EI as predictor of anxiety and depression. EI aspects (i.e., emotional clarity and repair) negatively predict anxiety. The results also reveal EI to be a predictor of depression, with EI component emotional clarity negatively predicting depression. Although it is recognized that anxiety and depression are two distinct internal processes, they are jointly discussed here because both are broadly considered as internalizing problems with covert, inner-directed symptoms (Frick, Barry, \& Kamphaus, 2009).

The results of this study are consistent with the study results of Berrocal, Alcaide, and Extremera (2006), who found that among their adolescent sample, emotional clarity and repair predict anxiety. They found that adolescents with better ability to discriminate among feelings and to regulate their moods showed less anxiety and depression.

Individuals who are able to understand their emotional states, those with emotional clarity are more likely to cope with their emotional problems, and thus, will have better mental health (Palmer, Donaldson, \& Stough, 2002). When people are able to name or recognize their inner feelings in stressful, situations, they are less likely to spend mental energy to attend to their emotional reactions. This, in turn, permits them to consider alternate solutions, keep their focus, and use more adaptive coping (Gohm \& Clore, 2002).

Emotional repair has also been shown to be related to general well-being as this allows individuals to maintain positive moods and disrupt negative ones (Extremera \& FernándezBerrocal, 2002). The ability to regulate moods is generally thought of as an earmark of emotional intelligence. However, Salovey et al. (1995) has shown that the maladaptive style of mood regulation relate to negative affect. Negative affect has been shown to involve excessive attention to the self. Persons in negative emotional states are likely to be absorbed by their problems, and in their inner worlds. Self-focus, or excessive emotional attention, will tend to intensify negative moods, increase negative beliefs, and implement unproductive regulative strategies, such as rumination, which in turn maintains negative moods and beliefs.

For this reason, anxiety is also referred to as a meta-worry, that is, worrying over one's worries. It is also possible that anxiety perpetuates itself: excessive emotional attention leads to rumination, which in turn may lead to negative beliefs and increased anxiety.

All EI theorists conceived of EI as related to negative emotionality: Bar-On (1997) had put forth in his EI framework three dimensions: general mood, stress management, and adaptation, which are negatively and directly, related to negative emotions. Goleman (1995) asserted that EI is a protective factor against negative moods. Mayer and Salovey (1997) suggested that an inability to appraise emotions may lead to ruminative coping, and is 
fundamental to negative emotionality. Future research may investigate the mediating role of emotional attention on the relationship of emotional clarity and repair, and anxiety or depression, and the relationships among the EI dimensions.

\section{SUMMARY AND CONCLUSION}

This study was conducted to examine the role of emotional intelligence to mental health, and the causal ordering of parenting, temperament, and EI on adolescent mental health. The results also provide support for the idea that emotionally intelligent individuals are more likely able adjust readily to situations, are less anxious and less depressed, thus, demonstrating the adaptive value of emotional intelligence. All these are significant for Filipino psychological research and are relevant in the understanding and enhancing the Filipino adolescents' mental and psychoemotional health.

There were two central research questions in this study: The first is concerned with the factors that predict emotional intelligence, and the second is focused on the ability of emotional intelligence to predict adolescent mental health. The results support the hypotheses previously put forth, that emotional intelligence predicts adolescent mental health. Specifically, EI was found to positively predict perceived selfefficacy and the sub dimension of resilience, mastery; and negatively predicted anxiety, depression, and another sub dimension of resilience, emotional reactivity.

In terms of general mental health, evidence from research is consistent with these results. In sum, total emotional intelligence positively predicts perceived self-efficacy and mastery, and negatively predicts emotional reactivity, depression, and anxiety. EI components, which were found to predict mental health, were emotional clarity and repair.

\section{RECOMMENDATIONS}

The findings of this study are relevant in that they reveal the importance of parenting styles, and the influence of temperament on emotional intelligence, and their combined impact to adolescent mental health.

Some general recommendations are presented as well.

For schools. While most EI research, even at the local front, have targeted adult samples, this study specifically targeted adolescents in college. In effect, the results provide a hint of our own students' EI and state of their mental health. There is some reason to say now that our students' EI is important to their sense of self-efficacy, optimism and adaptability, and that EI plays a role in their experience of distress. It may, then, be an appropriate time to explore the possibility of integrating emotional competencies in the curriculum at a time when educators are keen at looking for answers to student problems such as poor conduct, interpersonal conflict, and even, violence.

These "best practices" of implementing an emotional competency program in schools were recommended by Zeidner et al. (2006): that the program should be based on solid theoretical framework; that specific program goals for the target clients should focus on the strengthening of those components specified in the chosen EI framework. Once the EI framework and program goals are clearly mapped, they should be straightforward to develop the operational goals and strategies. EI proponents Salovey et al. (1999) recommended that EI programs should be fully integrated in the academic program, and not just an extra, separate "seminar-workshop," or additional course. The idea is to complement regular academic subjects with lessons and practice on emotional competencies, such as how to handle stress, anxiety, and frustration in a statistics class.

Additionally, emotional intelligence programs for college students may be integrated in the overall counseling programs in the colleges or universities to assist them cope with developmental transitions, life adjustments, emotional, and even academic issues. These college-based EI programs may include EI assessment, development, and research.

For counseling and clinical work. That EI is an important factor to mental health generally, and to self-efficacy, resilience, anxiety, and depression, specifically, is information that can add value to current counseling and clinical practice. Some recent trends on counseling and therapy are EI-based. For example, Greenberg and Pascual-Leone's (2006) emotion focused therapy suggest that the key to client change is helping client improve EI, by understanding, exploring, expressing, and re-forming the emotion in an empathic and genuine relationship. In this sense, the counselor or therapist can act as an "emotions coach," who helps the client become aware, accept, and make sense of his or her emotional experience.

\section{REFERENCES}

[1] Abraham, R. (2005). Emotioal Intelligence in the Workplace: A Review and Synthesis. In R. Schulze, R. D. Roberts, R. Schulze, R. D. Roberts (Eds.), Emotional intelligence: An international handbook (pp. 255-270). Ashland, OH US: Hogrefe \& Huber Publishers. Retrieved from EBSCOhost.

[2] Acock, A., Bengston, V., Klein, D., \& Anderson, P. Sourcebook of family theory and research. (2004). California: Sage.

[3] Adeyemo, D. (2007). Moderating influence of emotional intelligence on the link between academic self-efficacy and achievement of university students. Psychology and Developing Societies, 19(2), 199-213. doi:10.1177/097133360701900204.

[4] Ajna, Y., \& Susman, J. (2006). Understanding comorbidity with depression and anxiety disorders. JAOA, 106(5). Retrieved from http://www.jaoa.org

[5] Alegre, A., \& Benson, M. (2010). Parental behaviors and adolescent adjustment: Mediation via adolescent trait emotional intelligence. Individual Differences Research, 8(2), 83-96. Retrieved from PsycINFO database.

[6] Alegre, A. (2011). Parenting styles and children's emotional intelligence: What do we know? The Family Journal, 19(1), 5662. Retrieved from EBSCOhost.

[7] Alexander, L., Larosa, J., \& James, W. (2009). New dimensions in women's health. Canada: Jones and Bartlett Learning.

[8] Aron, E. N., \& Aron, A. (1997). Sensory-processing sensitivity and its relation to introversion and emotionality. Journal of Personality and Social Psychology, 73(2), 345368. doi:10.1037/0022-3514.73.2.345. 
[9] Asidao, Z. (2001). Emotional intelligence: Its influence on the job performance of managers of selected educational institutions in the division of City Schools, Manila. Unpublished doctoral dissertation, Technological University of the Philippines, Manila.

[10] Augusto-Landa, J., \& Montes-Berges, B. (2009). Perceived emotional intelligence, health and somatic symptomatology in nursing students. Individual Differences Research, 7(3), 197-211. Retrieved from PsycINFO database.

[11] Bandura, A. (1994). Self-efficacy. In V. S. Ramachaudran (Ed.), Encyclopedia of human behavior (Vol. 4, pp. 71-81). New York: Academic Press.

[12] Barber, B. K. (1996). Parental psychological control: Revisiting a neglected construct. Child Development, 67(6), 3296-3319. Database: PsycINFO

[13] Barlow, D. (2004). Anxiety and its disorders: The nature and treatment of anxiety and panic. New York: Guilford Press.

[14] Barlow, D. \& Durand, V. (2008). Abnormal psychology: An integrative approach. California: Cengage Learning.

[15] Bar-On, R. (1997). The emotional quotient inventory (EQ-i): Technical manual. Toronto: Multi-Health Systems.

[16] Bar-On, R. (2006). The Bar-On model of emotional-social intelligence (ESI). Psicothema, 18(Suppl), 13-25. Retrieved from EBSCOhost.

[17] Baron-Cohen, S. (2003). The essential difference: The truth about the male and female brain. New York, NY US: Basic Books. Retrieved from PsycINFO database.

[18] Beck, A., Ward, C H.., \& Mendelson, M. (1961). An inventory for measuring depression. Arch General Psychiatry, 4(561-71).

[19] Bradley, R., \& Corwyn, R. (2001). Home environment and behavioral development during early adolescence: The mediating and moderating roles of self-efficacy beliefs. Merrill-Palmer Quarterly: Journal of Developmental Psychology, 47(2), 165-187. doi:10.1353/mpq.2001.0007.

[20] Brody, L. R., \& Hall, J. A. (2008). Gender and emotion in context. In M. Lewis, J. M. Haviland-Jones, L. Barrett, M. Lewis, J. M. Haviland-Jones, L. Barrett (Eds.), Handbook of emotions (3rd ed.) (pp. 395-408). New York, NY US: Guilford Press. Retrieved from EBSCOhost.

[21] Bumphus, A. (2009). The emotional intelligence and resilience of school leaders: An investigation into leadership behaviors. Dissertation Abstracts International Section A, 69, Retrieved from EBSCOhost.

[22] Cha, C., \& Nock, M. (2009). Emotional intelligence is a protective factor for suicidal behavior. Journal of the American Academy of Child \& Adolescent Psychiatry, 48(4), 422-430. doi:10.1097/CHI.0b013e3181984f44.

[23] Chan, D. (2004, June). Perceived emotional intelligence and selfefficacy among Chinese secondary school teachers in Hong Kong. Personality \& Individual Differences, 36(8), 1781. doi:10.1016/j.paid.2003.07.007.

[24] Ciarrochi, J., Dean, F., \& Anderson, S. (2002). Emotional intelligence moderates the relationship between stress and mental health. Personality and Individual Differences, 32(2), 197-209. doi: 10.1016/S0191-8869(01)00012-5.

[25] Ciarrochi, J., Forgas, J., \& Mayer, J. (2001). Emotional intelligence in everyday life: A scientific inquiry. New York, NY US: Psychology Press. Retrieved from PsycINFO database.

[26] Ciarrochi, J., Deane, F., \& Anderson, S. (2002). Emotional intelligence moderates the relationship between stress and mental health. Personality and Individual Differences 32(1).197-20. doi: 10.1016/S0191-8869(01)00012-

[27] Ciarrochi, J., Chan, A., \& Bajgar, J. (2001). Measuring emotional intelligence in adolescents. Personality and Individual Differences, 31(7), 1105-1119. doi:10.1016/S01918869(00)00207-5.

[28] Ciarrochi, J. V., Chan, A. C., \& Caputi, P. (2000). A critical evaluation of the emotional intelligence construct. Personality and Individual Differences, 28(3), 539-561. doi:10.1016/S01918869(99)00119-1

[29] Christie, A., Jordan, P., Troth, A., \& Lawrence, S. (2007). Testing the links between emotional intelligence and motivation. Journal of Management \& Organization, 13(3), 212-226. Retrieved from PsycINFO database.

[30] Cole, P. (1986). Children's spontaneous control of facial expression. Child Development, 57(6), 1309-1321. doi:10.2307/1130411.

[31] Cohen, L., Manion, L., \& Morrison, K. (2007). Research methods in education (6th ed.). New York, NY US: Routledge/Taylor \& Francis Group. Retrieved from PsycINFO database.

[32] Cohen, J. (1977). Statistical power analysis for the behavioral sciences (rev. ed.). Hillsdale, NJ England: Lawrence Erlbaum Associates, Inc. Retrieved from EBSCOhost.

[33] Connor, B. \& Slear, S. (n.d.). Emotional intelligence and anxiety, emotional intelligence and resiliency. International Journal of Learning, 16(1), 249-260.

[34] Conger, J. (1973). Adolescence and youth: Psychological development in a changing world. Oxford England: Harper \& Row. Retrieved from PsycINFO database.

[35] Cooper, C., \& McConville, C. (1989). The factorial equivalence of state anxiety: Negative affect and state extraversion-positive affect. Personality and Individual Differences, 10(8), 919-920. doi:10.1016/0191-8869(89)90027-

[36] Di Fabio, A., \& Palazzeschi, L. (2008). Emotional intelligence and self-efficacy in a sample of Italian high school teachers. Social Behavior and Personality, 36(3), 315-326. doi:10.2224/sbp.2008.36.3.315

[37] Dinglasa, Q. (2004). Correlation of emotional intelligence to the academic performance of Notre Dame University Elementary Training Department pupils. Unpublished master's thesis, Notre Dame University, Cotabato City.

[38] Downey, L., Johnston, P., Hansen, K., Schembri, R., Stough, C., Tuckwell, V., et al. (2008). The relationship between emotional intelligence and depression in a clinical sample. The European Journal of Psychiatry, 22(2), 93-98. Retrieved from PsycINFO database.

[39] Downey, L., Johnston, P., Hansen, K., Birney, J., \& Stough, C. (2010). Investigating the mediating effects of emotional intelligence and coping on problem behaviours in adolescents. Australian Journal of Psychology, 62(1), 20-29. doi:10.1080/00049530903312873.

[40] Downey, L., Mountstephen, J., Lloyd, J., Hansen, K., \& Stough, C. (2008). Emotional intelligence and scholastic achievement in Australian adolescents. Australian Journal of Psychology, 60(1), 10-17. doi:10.1080/00049530701449505.

[41] Drago, J. M. (2005). The relationship between emotional intelligence and academic achievement in nontraditional college students. Dissertation Abstracts International, 65, Retrieved from EBSCOhost.

[42] Dulcan, M., \& Wiener, J. (2006). Essentials of child and adolescent psychiatry. Arlington, VA US: American Psychiatric Publishing, Inc. Retrieved from PsycINFO database.

[43] Elliot, A. (2005). Handbook of competence and motivation. New York: Guilford Press.

[44] Eisenberg, N., Fabes, R., Murphy, B., Shepard, S., Guthrie, I., Mazsk, P., et al. (1999). Prediction of elementary school children's socially appropriate and problem behavior from anger reactions at age 4-6 years. Journal of Applied Developmental Psychology, 20(1), 119-142. doi:10.1016/S0193-3973(99)800070 .

[45] Eisenberg, N., \& Fabes, R. A. (1995). The relation of young children's vicarious emotional responding to social competence, regulation, and emotionality. Cognition and Emotion, 9(2-3), 203228. doi:10.1080/02699939508409009

[46] Eisenberg, N., \& Fabes, R. A. (1995). The relation of young children's vicarious emotional responding to social competence, regulation, and emotionality. Cognition and Emotion, 9(2-3), 203228. doi:10.1080/02699939508409009

[47] Eisenberg, N., \& Morris, A. (2002). Children's emotion-related regulation. In R. V. Kail, R. V. Kail (Eds.), Advances in child development and behavior, Vol. 30 (pp. 189-229). San Diego, CA US: Academic Press. Retrieved from EBSCOhost. 
[48] Eisenberg, N., Fabes, R. A., Guthrie, I. K., \& Reiser, M. (2000). Dispositional emotionality and regulation: Their role in predicting quality of social functioning. Journal of Personality and Social Psychology, 78(1), 136-157. doi:10.1037/0022-3514.78.1.136.

[49] Extremera, N., \& Fernandez-Berrocal, P. (2006). Emotional intelligence as predictor to mental, social and physical health in university students. The Spanish Journal of Psychology, 9, 45-51. Retrieved from PsycINFO database.

[50] Extremera, N., Durán, A., \& Rey, L. (2007). Perceived emotional intelligence and dispositional optimism-pessimism: Analyzing their role in predicting psychological adjustment among adolescents. Personality and Individual Differences, 42(6), 10691079. doi:10.1016/j.paid.2006.09.014.

[51] Extremera, N., \& Fernández-Berrocal, P. (2002). Relation of perceived emotional intelligence and health-related quality of life of middle-aged women. Psychological Reports, 91(1), 47-59. doi:10.2466/PR0.91.5.47-59.

[52] Fernández-Berrocal, P., Alcaide, R., Extremera, N., \& Pizarro, D. (2006). The Role of Emotional Intelligence in Anxiety and Depression Among Adolescents. Individual Differences Research, 4(1), 16-27. Retrieved from EBSCOhost.

[53] Fernández-Berrocal, P., \& Extremera, N. (2006). Emotional intelligence and emotional reactivity and recovery in laboratory context. Psicothema, 18(Suppl), 72-78. Retrieved from EBSCOhost.

[54] Fonte, B. (2009). Relationship between parenting style, emotional intelligence and self esteem. Published doctoral dissertation. Washington College, Maryland. Retrieved from http://dspace.nitle.org/handle/10090/7271.

[55] Fredrickson, B. L., Mancuso, R. A., Branigan, C., \& Tugade, M. M. (2000). The undoing effect of positive emotions. Motivation and Emotion, 24(4), 237-258. doi:10.1023/A:1010796329158.

[56] Frick, P., Barry, C., \& Kamphaus, R. (2009). Clinical assessment of child and adolescent personality and behaviour. New York: Springer.

[57] Furlong, M. (2009). Handbook of positive psychology in schools. New York: Taylor and Francis.

[58] Galla, V. (2006). Emotional intelligence: Its relationship with managerial skills. Unpublished Doctoral dissertation. University of Cordilleras, Baguio City, Phillipines.

[59] Gist, M. E., \& Mitchell, T. R. (1992). Self-efficacy: A theoretical analysis of its determinants and malleability. Academy of Management Review, 17(2), 183-211. doi:10.2307/258770.

[60] Glicken, M. (2006). Learning from resilient people: Lessons we can apply to counseling and psychotherapy. California: Sage.

[61] Gohm, C. (2003). Mood regulation and emotional intelligence: Individual differences. Journal of Personality and Social Psychology, 84(3), 594-607. doi:10.1037/0022-3514.84.3.594.

[62] Gohm, C. L., \& Clore, G. L. (2002). Four latent traits of emotional experience and their involvement in well-being, coping, and attributional style. Cognition and Emotion, 16(4), 495-518. doi:10.1080/02699930143000374.

[63] Goleman, D. (1995). Emotional intelligence. New York: Bantam Books.

[64] Goleman, D. (1995). Emotional intelligence: Why it can matter more than IQ. New York: Bantam Books.

[65] Goleman, D. (1997). Emotional intelligence. New York: Bantam Books.

[66] Goleman, D. (1998). Working with emotional intelligence. London: Bloomsburry Publishing.

[67] Goozen, S. \& Van de Poll, N. (1994). Emotions: Essays on emotion. New Jersey: Routledge.

[68] Goldstein, S., \& Brooks, R. (2006). Handbook of resilience in children. New York: Springer.

[69] Gupta, G., \& Kumar, S. (2010). Mental health in relation to emotional intelligence and self efficacy among college students. Journal of the Indian Academy of Applied Psychology, 36(1), 61-67. Retrieved from PsycINFO database.

[70] Halberstadt, A. G., Denham, S. A., \& Dunsmore, J. C. (2001). Affective social competence. Social Development, 10(1), 79-119. doi:10.1111/1467-9507.00150.
[71] Hansen, K., Lloyd, J., \& Stough, C. (2009). Emotional intelligence and clinical disorders. Assessing emotional intelligence: Theory, research, and applications (pp. 219-237). New York, NY US: Springer Science + Business Media. Retrieved from PsycINFO database.

[72] Hargie, O., Saunders, C., \& Dickson, D. (1987). Social skills in interpersonal communication (2nd ed.). Cambridge, MA US: Brookline Books. Retrieved from PsycINFO database.

[73] Hartlage, S., Alloy, L. B., Vázquez, C., \& Dykman, B. (1993). Automatic and effortful processing in depression. Psychological Bulletin, 113(2), 247-278. doi:10.1037/0033-2909.113.2.247

[74] Huifang, Y., \& Jianping, G. (2007). Research on the emotional intelligence, self-efficacy and achievement motivation of business managers. Psychological Science (China), 30(3), 719-722. Retrieved from PsycINFO database.

[75] Izard, C. (2001). Emotional intelligence or adaptive emotions?. Emotion, 1(3), 249-257. doi:10.1037/15283542.1.3.249.

[76] Izard, C., Trentacosta, C., King, K., Morgan, J., \& Diaz, M. (2007). Emotions, emotionality, and intelligence in the development of adaptive behavior. In G. Matthews, M. Zeidner, R. D. Roberts, G. Matthews, M. Zeidner, R. D. Roberts (Eds.), The science of emotional intelligence: Knowns and unknowns (pp. 127-150). New York, NY US: Oxford University Press. Retrieved from EBSCOhost.

[77] Jerusalem, M., \& Schwarzer, R. (1992). Self-efficacy as a resource factor in stress appraisal processes. In R. Schwarzer (Ed.), Selfefficacy: Thought control of action (pp. 195-213). Washington, DC: Hemisphere.

[78] Kafetsios, K. (2004). Attachment and emotional intelligence abilities across the life course. Personality and Individual Differences, 37(1), 129-145. doi:10.1016/j.paid.2003.08.006.

[79] Kagan, J., Reznick, J., \& Snidman, N. (1988). The physiology and psychology of behavioral inhibition in children. Аnпual Progress in Child Psychiatry \& Child Development, 102-127. Retrieved from PsycINFO database.

[80] Kaplan, R., \& Saccuzzo, D. (2008). Psychological testing: Principles, applications, and issues. California: Cengage Learning.

[81] Keefer, K., Wood, L. M., \& Parker, J. D. A. (2009, June). Assessing emotional intelligence in children and adolescents: Congruence between self-report and parent ratings. Paper presented at the annual meeting of the Canadian Psychological Association, Montreal, Quebec.

[82] Keyes, C. (2009). The mental health continuum: From languishing to flourishing in life (2002).Foundations of psychological thought: A history of psychology (pp. 601-617). Thousand Oaks, CA US: Sage Publications, Inc. Retrieved from PsycINFO database.

[83] Kochanska, G., \& Coy, K. (2002). Child emotionality and maternal responsiveness as predictors of reunion behaviors in the Strange Situation: Links mediated and unmediated by separation distress. Child Development, 73(1), 228-240. doi:10.1111/14678624.00402 .

[84] Kochanska, G., Coy, K., \& Murray, K. (2001). The development of self-regulation in the first four years of life. Child Development, 72(4), 1091-1111. doi:10.1111/1467-8624.00336.

[85] Koven, N., Roth, R., Garlinghouse, M., Flashman, L., \& Saykin, A. (2010). Regional gray mattery correlates of perceived emotional intelligence. Social Cognitive Affect Neuroscience. doi: $10.1093 / \mathrm{scan} / \mathrm{nsq} 084$.

[86] Landy, F. (2006). The Long, Frustrating, and Fruitless Search for Social Intelligence: A Cautionary Tale. A critique of emotional intelligence: What are the problems and how can they be fixed? (pp. 81-123). Mahwah, NJ US: Lawrence Erlbaum Associates Publishers. Retrieved from PsycINFO database.

[87] Lewis, M., Haviland-Jones, J., \& Barrett, L. (2008). Handbook of emotions (3rd ed.). New York, NY US: Guilford Press. Retrieved from PsycINFO database.

[88] Lochman, J., \& Lenhart, L. (1993). Anger coping intervention for aggressive children: Conceptual models and outcome effects. 
Clinical Psychology Review, 13(8), 785-805. doi:10.1016/S02727358(05)80006-6.

[89] Lucas, R. E., \& Baird, B. M. (2004). Extraversion and Emotional Reactivity. Journal of Personality and Social Psychology, 86(3), 473-485. doi:10.1037/0022-3514.86.3.473.

[90] Luthar, S. (2003). Resilience and vulnerability: Adaptation in the context of childhood adversities. Cambridge: Cambridge University Press.

[91] Malekar, S., \& Mohanty, R.P. (2009). Factors affecting emotional intelligence: An empirical study for some school students in India. International Journal of Management in Education, 3, pp. 8-28.

[92] Manzano, A. (2004). Relationship between emotional intelligence and academic performance. Unpublished master's thesis. University of San Carlos, Cebu City, Phillippines.

[93] Martinez-Pons, M. (1997). The relation of emotional intelligence with selected areas of personal functioning. Imagination, Cognition and Personality, 17(1), 3-13. doi:10.2190/68VDDFXB-K5AW-PQAY

[94] Matthews, G. (1997). Cognitive science perspectives on personality and emotion. Amsterdam: Elsevier.

[95] Matthews, G., \& Funke, G. J. (2006). Worry and Informationprocessing. In G. L. Davey, A. Wells, G. L. Davey, \& A. Wells (Eds.) ,Worry and its psychological disorders: Theory, assessment and treatment (pp. 51-67). Hoboken, NJ US: Wiley Publishing. doi:10.1002/9780470713143.ch4

[96] Martinez-Pons, M. (1997). The relation of emotional intelligence with selected areas of personal functioning. Imagination, Cognition and Personality, 17(1), 3-13. doi:10.2190/68VDDFXB-K5AW-PQAY.

[97] Matthews, G. (1997 ). Cognitive science perspectives on personality and emotion. Amsterdam: Elsevier.

[98] Mayer, J. (2004). What Are the Advantages of a More Focused Approach to EI? Retrieved from http://www.unh.edu/emotional_intelligence.

[99] Mayer, J. D., \& Gaschke, Y. N. (1988). The experience and metaexperience of mood. Journal of Personality and Social Psychology, 55(1), 102-111. doi:10.1037/0022-3514.55.1.102

[100] Mayer, J., \& Geher, G. (1996). Emotional intelligence and the identification of emotion. Intelligence, 22(2), 89-114. doi:10.1016/S0160-2896(96)90011-2.

[101] Mayer, J., \& Salovey, P. (1995). Emotional intelligence and the construction and regulation of feelings. Applied \& Preventive Psychology, 4(3), 197-208. doi:10.1016/S0962-1849(05)80058-7.

[102] Mayer, J., \& Salovey, P. (1995). Emotional intelligence and the construction and regulation of feelings.Applied \& Preventive Psychology, 4(3), 197-208. doi:10.1016/S0962-1849(05)80058-7

[103] Mayer, J. \& Salovey, P. (1997). Emotional development and emotional intelligence. Cambridge University Press: New York.

[104] Mayer, J. D., \& Ciarrochi, J. (2006). Clarifying concepts related to emotional intelligence: A proposed glossary. In J. Ciarrochi, J. Forgas, \& J. D. Mayer (Eds). Emotional intelligence in everyday life (2nd ed). New York: Psychological Press.

[105] Mayer, J., Salovey, P., \& Caruso, D. (2004). Emotional intelligence: Theory, findings, and implications. Psychological Inquiry, 15(3), 197-215. doi:10.1207/s15327965pli1503_02.

[106] Mayer, J., Caruso, D., \& Salovey, P. (1999). Emotional intelligence meets traditional standards for an intelligence. Intelligence, 27(4), 267-298. doi:10.1016/S01602896(99)00016-1.

[107] Mayer, J. D., Perkins, D. M., Caruso, D. R., \& Salovey, P. (2001). Emotional intelligence and giftedness.Roeper Review, 23(3), 131137. doi:10.1080/02783190109554084.

[108] Mayer, J., Salovey, P., \& Caruso, D. (2000). Models of emotional intelligence. In R. Sternberg (Ed.), Handbook of intelligence. Cambridge, UK: Cambridge University Press

[109] Mayer, J., \& Salovey, P. (1995). Emotional intelligence and the construction and regulation of feelings. Applied \& Preventive Psychology, 4(3), 197-208. doi:10.1016/S0962-1849(05)80058-7
[110] Mayer, J., \& Salovey, P. (1997). What is emotional intelligence? In P. Salovey \& D. J. Sluyter(Eds.), Emotional development and emotional intelligence (pp. 3-31). New York: Basic Books.

[111] Mayer, J., Salovey, P., Caruso, D., \& Sitarenios, G. (2003). Measuring emotional intelligence with MSCEIT V2.0. Emotion, 3, 97-105. DOI: $10.1037 / 1528-3542.3 .1 .97$

[112] Merriam, s. (2008). Third update on adult learning theory. University Drive, San Marcos, Texas:John Wiley and Sons.

[113] Meyers, L., Gamst, G., \& Guarino, A.J. (2006). Applied multivariate research: Design and interpretation. London: Sage.

[114] Mikolajczak, M., Petrides, K., \& Hurry, J. (2009, June). Adolescents choosing self-harm as an emotion regulation strategy: The protective role of trait emotional intelligence. British Journal of Clinical Psychology, 48(2), 181-193. Retrieved July 26, 2009, doi:10.1348/014466S08X386027.

[115] Natano, C. (2001). Emotional intelligence: its relationship to the decision-making styles among the tertiary school administrators in the Cotabato Area. Unpublished doctoral dissertation. Notre Dame University, Cotabato City, Philippines.

[116] National Research Council. (2008). Adolescent health services: missing opportunities. Washington: National Academies Press.

[117] Natividad, M. (2006). Levels of depression among Xavier University students. Unpublished master's thesis. Xavier University, Cagayan de Oro, Philippines.

[118] Nixon, C. \& Watson,A. (1999) Adolescence: The mediating and Moderating Roles of Self-Efficacy Beliefs. Merrill-Palmer Quarterly 47, (2), 165187.

[119] O'Connor, R. , \& Little, I. S. (2003). Revisiting the correlational validity of emotional intelligence: Self-report versus ability-based measures. Personality and Individual Differences, 35(8), 18931902. doi:10.1016/S0191-8869(03)00038-2

[120] Connor, K. M., \& Zhang, W. (2006). Resilience: Determinants, Measurement, and Treatment Responsiveness. CNS Spectrums, 11(10,Supp112), 5-12. Retrieved from EBSCOhost.

[121] Palmer, B., Donaldson, C., \& Stough, C. (2008). Emotional intelligence and life satisfaction. In J. C. Cassady, M. Eissa, J. C. Cassady, M. Eissa (Eds.), Emotional intelligence: Perspectives on educational and positive psychology (pp. 131-143). New York, NY US: Peter Lang Publishing. Retrieved from EBSCOhost.

[122] Penrose, A., Perry, C., \& Ball, I. (2007, April). Emotional intelligence and teacher self efficacy: The contribution of teacher status and length of experience. Issues in Educational Research, 17(1), 107-126 from Education Research Complete database.

[123] Petrides, K. V., \& Furnham, A. (2000). Gender differences in measured and self-estimated trait emotional intelligence. Sex Roles, 42(5-6), 449-461. doi:10.1023/A:1007006523133.

[124] Petrides, K. V., Furnham, A., \& Mavroveli, S. (2007). Trait emotional intelligence: Moving forward in the field of EI. In G. Matthews, M. Zeidner, R. D. Roberts, G. Matthews, M. Zeidner, R. D. Roberts (Eds.), The science of emotional intelligence: Knowns and unknowns (pp. 151-166). New York, NY US: Oxford University Press. Retrieved from EBSCOhost.

[125] Pichayapinyo. P., Pawwattana, A., \& Thongvichaen, S. (2008). Parenting styles, Emotional intelligence, and Intelligence quotients in Thai school-aged children in Tukdang community, Bangkok Metropolis. Journal of Public Health, 38(1). Retrieved from http://thailand.digitaljournals.org/index. $\mathrm{php} / \mathrm{JPH} /$ article/viewFile/2866/2889

[126] Prince-Embury, S. (2007). Resiliency Scales for children and adolescents: A profile of personal strengths. Minneapolis: NCS Pearson.

[127] Prince-Embury, S. (2010). Psychometric properties of the Resiliency Scales for Children and Adolescents and use for youth with psychiatric disorders. Journal of Psychoeducational Assessment, 28(4), 291-302. doi:10.1177/0734282910366832.

[128] Prince-Embury, S. \& Courville, T. (2008). Comparison of One-, Two-, and Three-Factor Models of Personal Resiliency Using the Resiliency Scales for Children and Adolescents. Canadian Journal of School Psychology 23,111-25. doi:10.1177/0829573508316589. 
[129] Rabazo Mendez, M. J., \& Moreno, Manso, J. M. (2006). Interactive style during the reading of children's stories with deceptive contents. Revista Electronica de Investigacion Psycoeducativa, 4(3), 493-512.

[130] Reiff, H. B., Hatzes, N. M., Bramel, M. H., \& Gibbon, T. (2001). The relation of $\mathrm{LD}$ and gender with emotional intelligence in college students. Journal of Learning Disabilities, 34(1), 66-78. doi:10.1177/002221940103400106.

[131] Rothbart, M., Ahadi, S., \& Evans, D. (2000). Temperament and personality: Origins and outcomes. Journal of Personality and Social Psychology, 78(1), 122-135. doi:10.1037/00223514.78.1.122.

[132] Rothbart, M. K., Ellis, L. K., \& Posner, M. I. (2011). Temperament and self-regulation. In K. D. Vohs, R. F Baumeister, K. D. Vohs, \& R. F. Baumeister (Eds.), Handbook of self-regulation: Research, theory, and applications (2nd ed., pp. 441-460). New York, NY US: Guilford Press. Retrieved from EBSCOhost.

[133] Rubin, K., Bukowski, W., \& Laursen, B. (2009). Handbook of peer interactions, relationships, and groups. New York, NY US: Guilford Press. Retrieved from PsycINFO database.

[134] Rusting, C. L., \& Larsen, R. J. (1997). Extraversion, neuroticism, and susceptibility to positive and negative affect: A test of two theoretical models. Personality and Individual Differences, 22(5), 607-612. doi:10.1016/S0191-8869(96)00246-2.

[135] Sánchez-Núñez, M., Fernández-Berrocal, P., Montañés, J., \& Latorre, J. (2008). Does emotional intelligence depend on gender? The socialization of emotional competencies in men and women and its implications. Electronic Journal of Research in Educational Psychology, 6(2), 455-474. Retrieved from PsycINFO database.

[136] Saarni, C. (1999). The development of emotional competence. New York: Guilford Press.

[137] Sarma, K. (2008). Mental resilience: The power of clarity: How to develop the focus of a warrior and the peace of a monk. California: New World Library.

[138] Salovey, P., Woolery, A., \& Mayer, J. (2002). Emotional intelligence: conceptualization and measurement. In. G.J.O. Fletcher, G. Fletcher, \& M.S. Clark (Eds.), Blackwell handbook in social psychology (pp. 279-307). Oxford, UK.Wiley-Blackwell.

[139] Salovey, P. , \& Mayer, J. D. (1990). Emotional intelligence. Imagination, Cognition, and Personality, 9, 185-211.

[140] Salovey, P., Mayer, J., Goldman, S., Turvey, C., \& Palfai, T. (1995). Emotional attention, clarity, and repair: Exploring emotional intelligence using the Trait Meta-Mood Scale. Emotion, Disclosure, \& Health, 125-154. Washington, DC US: American Psychological Association. doi:10.1037/10182-006.

[141] Saluja, G., Iachan, R., Scheidt, C. Overpeck, M., Sun, W., \& Giedd, W. (2004). Prevalence of and Risk Factors for Depressive Symptoms Among Young Adolescents. Arch Pediatric Adolescent.

[142] Scharfe, E. (2000). Development of emotional expression, understanding, and regulation in infants and young children. In E. Scharfe, The handbook of emotional intelligence: Theory, development, assessment, and application at home, school, and in the workplace (pp. 244-262). San Francisco, CA US: Jossey-Bass. Retrieved from PsycINFO database.

[143] Schwarzer, R., \& Jerusalem, M. (1995). Generalized SelfEfficacy scale. In J. Weinman, S. Wright, \& M. Johnston, Measures in health psychology: A user's portfolio. Causal and control beliefs (pp. 35-37). Windsor, England: NFER-NELSON.

[144] Serrat, O. (2009). Understanding and developing emotional intelligence. Knowledge Solutions. Retrieved from http://www.adb.org/documents Medicine. 2004; 158:760-765.

[145] Siu, A. (2009). Trait emotional intelligence and its relationships with problem behavior in Hong Kong adolescents. Personality and Individual Differences, 47(6), 553-557. doi:10.1016/j.paid.2009.05.004.

[146] Spielberger, C. D., \& Reheiser, E. C. (2004). Anxiety: Its meaning and measurement. In N. B. Anderson (Ed.), Encyclopedia of
Health and Behavior (pp. 59-62). Thousand Oaks, CA: Sage Publications Inc.

[147] Sta. Maria, L. (2007). Emotional intelligence: Its relationship to academic achievement. Unpublished master's thesis. Adventist University of the Philippines, Silang, Cavite

[148] Steer, R., Ball, R., Ranieri, W., \& Beck, A. (1997). Further evidence for the construct validity of the Beck Depression Inventory-II with psychiatric outpatients. Psychological Reports, 80(2), 443-446. Retrieved from PsycINFO database.

[149] Stein, N. L., Trabasso, T., \& Liwag, M. (1993). The representation and organization of emotional experience: Unfolding the emotion episode. In M. Lewis, J. M. Haviland, M. Lewis, J. M. Haviland (Eds.), Handbook of emotions (pp. 279300). New York, NY US: Guilford Press. Retrieved from EBSCOhost

[150] Stein, D., \& Hollander, E. (2001). The American psychiatric publishing textbook of anxiety disorders. Arlington, VA: American Psychiatric Publication.

[151] Sternberg, R. (1997). The concept of intelligence and its role in lifelong learning and success. American Psychologist, 52(10), 1030-1037. doi:10.1037/0003-066X.52.10.1030.

[152] Stough, C., Saklofske, D., \& Parker, J. (2009). A brief analysis of 20 years of emotional intelligence: An introduction to assessing emotional intelligence: Theory, research, and applications. Assessing emotional intelligence: Theory, research, and applications (pp. 3-8). New York, NY US: Springer Science + Business Media. doi:10.1007/978-0-387-88370-0_1

[153] Summerfeldt, L., Kloosterman, P., Antony, M., \& Parker, J. (2006). Social anxiety, emotional intelligence, and interpersonal adjustment. Journal of Psychopathology and Behavioral Assessment, 28(1), 57-68. doi:10.1007/s10862-006-4542-1.

[154] Velasco, C., Fernández, I., Páez, D., \& Campos, M. (2006). Perceived emotional intelligence, alexithymia, coping and emotional regulation. Psicothema, 18(Suppl), 89-94. Retrieved from PsycINFO database.

[155] Wells, A., \& Matthews, G. (1994). Attention and emotion: A clinical perspective. Hillsdale, NJ England: Lawrence Erlbaum Associates, Inc. Retrieved from EBSCOhost.

[156] Whisman, M., Perez, J., \& Ramel, W. (2000). Factor structure of the Beck Depression Inventory-Second Edition (BDI-II) in a student sample. Journal of Clinical Psychology, 56(4), 545-551. doi:10.1002/(SICI)1097-4679(200004)56:4<545::AID-

JCLP7> 3.0.CO;2-U

[157] Wolf, D., \& Mash, E. (2005). Behavioral and emotional disorders in adolescents. New York: Guilford Press.

[158] Wolfradt, U., Hempel, S., \& Miles, J. V. (2003). Perceived parenting styles, depersonalisation, anxiety and coping behavior in adolescents. Personality and Individual Differences, 34(3), 521532. doi:10.1016/S0191-8869(02)00092-2.

[159] Wong, S., \& Ang, R. (2007). Emotional competencies and maladjustment in Singaporean adolescents.Personality and Individual Differences, 43(8), 2193-2204. doi:10.1016/j.paid.2007.06.033.

[160] World Health Organization. (2005). Promoting Mental Health: Concepts, Emerging evidence, Practice: A report of the World Health Organization, Department of Mental Health and Substance Abuse in collaboration with the Victorian Health Promotion Foundation and the University of Melbourne. Geneva: Author.

[161] Yoo, S., \& Salovey, P. (2008). Emotional intelligence and emotional responses to hypothetical and actual frustrating stressors. Imagination, Cognition and Personality, 28(3), 239249. doi:10.2190/IC.28.3.c.

[162] Zahn-Waxler, C., Radke-Yarrow, M., \& King, R.A. (1979). Child rearing and children's prosocial initiations towards victims of distress. Child Development, 50, 319-330.

[163] Zahn-Waxler, C., Cummings, E., McKnew, D. H., \& RadkeYarrow, M. (1984). Altruism, aggression, and social interactions in young children with a manic-depressive parent. Child Development, 55(1), 112-122. doi:10.2307/1129838.

[164] Zeidner, M., Matthews, G., Roberts, R., \& MacCann, C. (2003). Development of emotional intelligence: Towards a multi-level 
investment model. Human Development, 46(2-3), 69-96. doi:10.1159/000068580.

[165] Zeidner, M., Matthews, G., \& Roberts, R. (2009). What we know about emotional intelligence: How it affects learning, work, relationships, and our mental health. Cambridge, MIT Press.
[166] Zeman, J., \& Garber, J. (1996). Display rules for anger, sadness, and pain: It depends on who is watching. Child Development, 67(3), 957-973. doi:10.2307/1131873.

[167] Zimmerman, B., Bandura, A., \& Martinez-Pons, M. (1992). Selfmotivation for academic attainment: The role of self-efficacy beliefs and personal goal setting. American Educational Research Journal, 29(3), 663-676. doi:10.2307/1163261. 